\title{
Comunicação
}

[Communication]

\section{Pesquisa do vírus da diarreia viral bovina em touros mantidos a campo no estado do Rio Grande do Sul}

[Bovine viral diarrhea virus in bulls from the Rio Grande do Sul state]

\author{
A.K. Mascitti ${ }^{1}$, A.P. Fraga ${ }^{*}$, J.P.R. Abreu ${ }^{1}$, M.N. Weber ${ }^{3}$, P.F. Salla ${ }^{1}$, M.V.S. Corrêa ${ }^{1}$, \\ N. Ikuta ${ }^{1,2}$, C.W. Canal ${ }^{3}$, V.R. Lunge ${ }^{1,2}$ \\ ${ }^{1}$ Laboratório de Diagnóstico Molecular - ULBRA - Canoas, RS \\ ${ }^{2}$ Simbios Biotecnologia - Cachoeirinha, RS \\ ${ }^{3}$ Universidade Federal do Rio Grande do Sul - UFRGS - Porto Alegre, RS
}

O Brasil é o segundo maior produtor e o primeiro em exportações de carne bovina do mundo. O Rio Grande do Sul possui em torno de 5\% do rebanho brasileiro, a maioria de gado de corte, criado extensivamente em propriedades das regiões Central, Sudoeste e Sudeste do estado. Esses animais são suscetíveis a diferentes doenças que interferem na produtividade e resultam em importantes perdas econômicas, entre as quais a diarreia viral bovina (Baker, 1995). O agente etiológico dessa doença é um Pestivirus (BVDV, Bovine viral diarrhea virus), da família Flaviviridae (Flores et al., 2005). A infecção pelo BVDV pode cursar de forma assintomática ou apresentar diferentes formas clínicas, com sinais respiratórios, digestivos e reprodutivos, além de imunossupressão. Animais persistentemente infectados (PI) resultam da infecção intrauterina pelo BVDV no período de 20 a 120 dias de gestação. Animais PI são imunotolerantes, incapazes de eliminar o vírus e constituem uma fonte contínua de excreção através de secreções. Em geral, esses animais morrem até o segundo ano de vida, devido a infecções secundárias ou doença das mucosas (DM), mas alguns chegam a idade adulta e entram em reprodução, contaminando outros animais do rebanho (Baker, 1995).

A transmissão dentro do rebanho ocorre de forma vertical ou horizontal. A transmissão vertical pode causar problemas reprodutivos, como abortamentos e fetos com malformações

Recebido em 20 de junho de 2016

Aceito em 8 de setembro de 2016

*Autor para correspondência (corresponding author)

E-mail: alinefraga.vet@gmail.com congênitas, além de animais PI. A forma horizontal resulta normalmente em animais com infecção aguda transitória, sendo o BVDV transmitido durante o coito, pelo contato focinho a focinho, mucosa a mucosa ou ainda pelas excreções e fômites. Especificamente os touros podem transmitir o vírus para as vacas durante a monta natural, no campo, ou pelo uso de sêmen contaminado, durante a inseminação artificial (Walz et al., 2010). Dados demonstram que, após infecção aguda, o vírus pode permanecer no tecido testicular por até sete meses (Givens et al., 2003). Além disso, um estudo detectou o RNA viral em sêmen de animais por até 2,7 anos (Givens et al., 2009). Desta forma, a identificação do BVDV em touros é essencial para que esses animais não disseminem o vírus. Cada reprodutor cobre entre 25 e 30 fêmeas em um único período reprodutivo, podendo contaminar várias fêmeas no rebanho, o que causa perdas reprodutivas com ou sem a ocorrência de animais PI (Walz et al., 2010).

Estudos prévios relataram a presença de BVDV em amostras com suspeita de infecção pelo BVDV no estado do Rio Grande do Sul (Oliveira et al., 1996; Botton et al., 1998; Canal et al., 1998). Entretanto, não investigaram a presença do BVDV em reprodutores mantidos a campo. O objetivo deste estudo foi pesquisar a ocorrência do BVDV em amostras de soro de touros de campo de estabelecimentos pecuários das regiões Centro-Ocidental, Sudoeste e Sudeste do Rio Grande do Sul. 
Foram coletadas amostras de soro de 445 touros, com idade superior a seis meses, em 20 estabelecimentos de três diferentes mesorregiões do estado do Rio Grande do Sul, sendo 16 propriedades em municípios da região Sudoeste (Bagé, Aceguá, Dom Pedrito, Santana do Livramento e Quaraí), duas da Centro-Ocidental (Formigueiro e São Sepé) e duas da Sudeste (Pelotas e Candiota) (Fig. 1). Cada touro foi avaliado clinicamente, com registro de vacinações e ocorrência de sinais clínicos sugestivos de processos infecciosos ou de alterações no sistema reprodutivo. A coleta de coleta de sangue foi realizada por punção da veia jugular. O soro foi separado e mantido em $-20^{\circ} \mathrm{C}$ até a análise. Amostras de sêmen também foram coletadas (por eletroejaculação) e armazenadas em freezer a $-20^{\circ} \mathrm{C}$. As amostras de soro foram analisadas em pools de cinco amostras. Alíquotas de $0,1 \mathrm{~mL}$ de cada pool (e de cada soro quando o pool foi positivo) e $0,1 \mathrm{~mL}$ de cada amostra de sêmen foram submetidas ao procedimento de extração de RNA pelo método de adsorção em sílica, utilizando reagentes comerciais NewGene (Simbios Biotecnologia, Cachoeirinha, RS, Brasil).

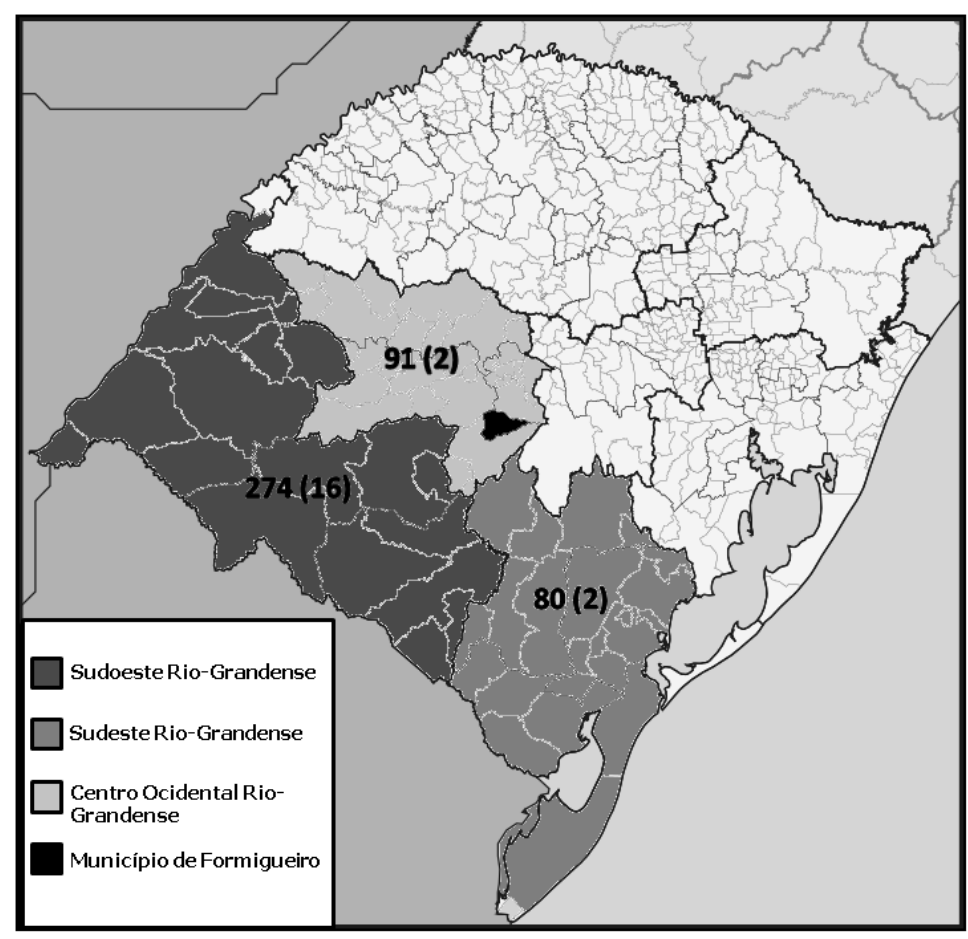

Figura 1. Mapa com as mesorregiões amostradas no estudo, identificando o número de amostras coletadas (propriedades amostradas).

As reações de RT-PCR foram baseadas em procedimento descrito previamente (Vilcek et al., 1994). Em cada reação, foram utilizados $2 \mu \mathrm{L}$ de RNA extraído, $0,75 \mu \mathrm{L}$ dos primers $324 \mathrm{~F}$ e 326R (20pmol $/ \mu \mathrm{L}$ cada), $0,08 \mu \mathrm{L}$ de dNTPs $(25 \mathrm{mM}), 0,75 \mu \mathrm{L}$ de DTT $(0,1 \mathrm{M}), 30 \mathrm{U}$ de RT MMLV (Promega, Madison, WI, EUA), 1,5U de Taq DNA polimerase (Cenbiot Enzimas, Porto Alegre, RS, Brasil) em um volume de $30 \mu \mathrm{L}$. As reações de amplificação foram realizadas em termociclador Veriti 96 (Applied Biosystems Inc., Norwalk, CT, EUA), com as seguintes condições de amplificação: 1 ciclo de $37^{\circ} \mathrm{C}$ por
$30 \mathrm{~min}, 94^{\circ} \mathrm{C}$ por $3 \mathrm{~min}$, e 35 ciclos de $94^{\circ} \mathrm{C}$ por $60 \mathrm{seg}, 56^{\circ} \mathrm{C}$ por $60 \mathrm{seg}$ e $72^{\circ} \mathrm{C}$ por $60 \mathrm{seg}$ e um ciclo de extensão final a $72^{\circ} \mathrm{C}$ por $7 \mathrm{~min}$. Os produtos de PCR foram submetidos à eletroforese em gel de poliacrilamida $10 \%$ e corados com nitrato de prata. As reações de sequenciamento utilizaram os mesmos primers de RT-PCR e foram analisadas em sequenciador ABI 3130xl (Applied Biosystems Inc., Norwalk, CT, EUA). As sequências de nucleotídeos, de ambos os sentidos, foram editadas e montadas, utilizando-se o software SeqMan. O alinhamento foi realizado pelo método ClustalW, do software 
MegAlign (DNAStar, Madison, Wisconsin, EUA). A análise filogenética foi realizada mediante o uso do software MEGA 6.0, com o método de inferência Neighbor-Joining, modelo estatístico Kimura-2, em 1000 réplicas.

A detecção do BVDV por RT-PCR foi realizada a partir do soro de 445 touros, organizados em 89 pools. Um único pool apresentou amplificação do fragmento de tamanho esperado (288pb) e a análise individual dessas cinco amostras resultou em apenas um caso positivo (A36). O sêmen coletado desse touro também apresentou detecção positiva para BVDV por RT-PCR. Esse animal pertencia a um estabelecimento que não realizou vacinação, localizado no município de Formigueiro, região Centro-Ocidental do Rio Grande do Sul (Fig. 1). Não foi observado nenhum caso positivo nas demais regiões (Sudoeste e Sudeste).

A análise pelo BLAST demonstrou que a amostra A36 apresentou sequência similar ao BVDV, apresentando $99 \%$ de identidade com o isolado UEL3-BR/07 (número de acesso no GenBank JQ513588), detectado no Brasil, no estado do Paraná e caracterizado como BVDV1a (Otonel et al., 2014). A árvore filogenética construída com sequências de referência mostrou robustez, com valores de bootstrap acima de $88 \%$ nos agrupamentos dos subtipos de BVDV1, possibilitando classificar a amostra A36 como BVDV-1a (Fig. 2).

A maioria dos estudos epidemiológicos realizados com rebanhos bovinos, nas últimas décadas, no Rio Grande do Sul, analisou a ocorrência de resposta sorológica para o BVDV. A análise de 430 bovinos de 19 propriedades pelo teste de ELISA demonstrou 56\% de animais soropositivos (Canal et al., 1998). Dados de soroneutralização e ELISA de diferentes regiões do estado demonstraram índices de positividade variando de 8,0\% a 73,5\% (Flores et al., 2005). Entretanto, essas informações devem ser interpretadas com cautela, pois foram obtidas da análise de casos suspeitos (e não de todo o rebanho de um estabelecimento/região). Tais índices indicam a presença da infecção em subpopulações específicas e não em todo o rebanho bovino (Flores et al., 2005).

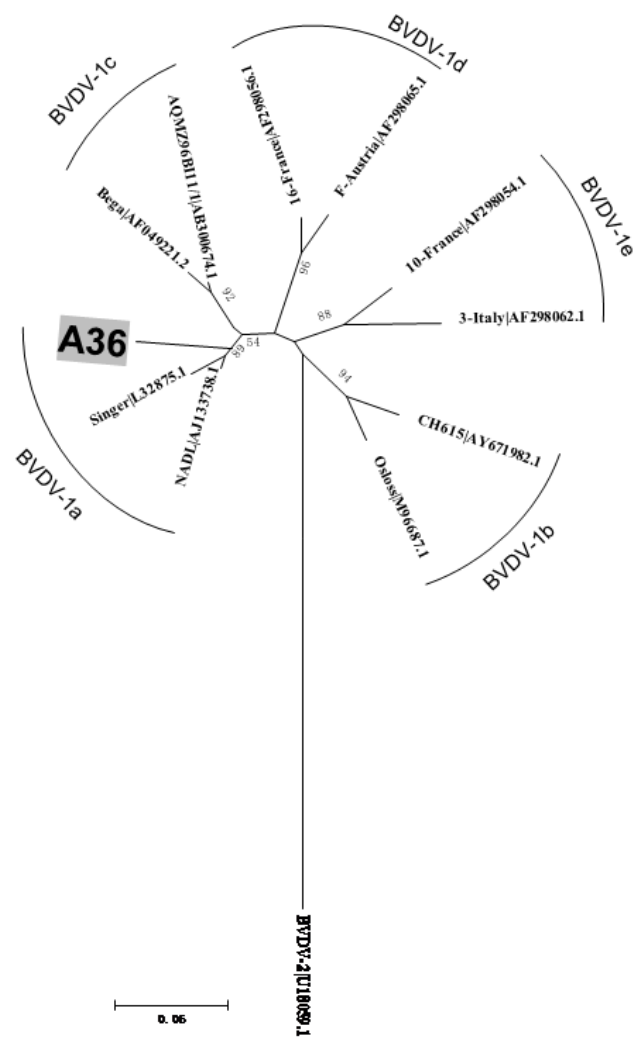

Figura 2. Árvore filogenética de fragmentos da região 5'UTR, construída pelo método NeighborJoining, com 1000 bootstrap, usando-se o programa MEGA6.

Por outro lado, os estudos de isolamento de BVDV em rebanhos com problemas reprodutivos no Rio Grande do Sul demonstraram índices de 1,2\% e 0,8\% (Oliveira et al., 1996; Botton et al., 1998). Pesquisas que realizaram a detecção direta desse vírus nos rebanhos por RT-PCR já foram realizadas, mas apenas para confirmação da ocorrência do BVDV em casos clinicamente comprovados e/ou restritos a determinadas propriedades e/ou localidades (Dezen et al., 2013). Os resultados do presente trabalho demonstraram uma baixa ocorrência do BVDV em touros (apenas um caso) na análise de três mesorregiões do estado. Estudo similar foi realizado nos Estados Unidos (estados de Alabama, Mississippi e Tennessee) e não foi encontrado nenhum animal positivo em 558 touros analisados. Os autores do estudo consideraram uma prevalência máxima de $0,54 \%$ nessa região dos Estados Unidos (Givens et al., 2003). 
Com relação à análise filogenética, a amostra A36 foi identificada como BVDV-1a, subtipo previamente demonstrado no estado do Rio Grande do Sul (Bianchi et al., 2011). O touro positivo e os demais animais da mesma propriedade não apresentavam manifestações clínicas associadas à infecção por BVDV. Além disso, não foram percebidas alterações no sêmen do animal positivo com base nos resultados de exame andrológico (dados não mostrados). Touros são disseminadores diretos de inúmeras doenças infecciosas, entre elas a diarreia viral bovina. A manutenção desses animais no rebanho pode resultar na transmissão do BVDV para as fêmeas, levando a prejuízos reprodutivos, além da possível introdução de animais PI no rebanho (Walz et al., 2010). A infecção pelo BVDV normalmente não resulta em lesões características nos órgãos reprodutores, mas esse vírus é transmitido pela via sexual, causando uma série de patologias reprodutivas e normalmente está presente no sêmen de touros com infecção aguda transitória e/ou persistentemente infectados. Mesmo animais não virêmicos podem ter infecções testiculares prolongadas pelo BVDV, levando à diminuição da motilidade do sêmen e ao aumento de anomalias morfológicas (Givens et al., 2009). A baixa detecção do BVDV pode ser explicada pelo manejo eficiente nos estabelecimentos analisados e pelas boas condições sanitárias dos rebanhos. Além disso, não havia relatos de problemas reprodutivos causados pelo BVDV nas propriedades amostradas.

Palavras-chave: BVDV, RT-PCR, diagnóstico

\section{COMITÊ DE ÉTICA E BIOSSEGURANÇA}

O projeto "Prevalência do vírus da diarreia viral bovina em sêmen de touros a campo em municípios na região da campanha do Rio Grande do Sul" foi aprovado pela Comissão de Ética no Uso de Animais da ULBRACEUA/ULBRA (protocolo 2011-9P).

\section{AGRADECIMENTOS}

Aos alunos e técnicos do Laboratório de Reprodução Animal (Laran) da Universidade da Região da Campanha (URCAMP) de Bagé (RS), pelo auxílio na realização das avaliações clínicas gerais dos animais e nas coletas de amostras a campo. À equipe do Laboratório de Diagnóstico Molecular da Universidade Luterana do Brasil (ULBRA) de Canoas (RS), em especial à bióloga Fernanda Kieling Moreira Lehmann, pelo suporte técnico na realização das análises de biologia molecular.

\section{REFERÊNCIAS}

BAKER, J.C. The clinical manifestations of bovine viral diarrhea infection. Vet. Clin. N. Am. Food Anim. Pract., v.11, p.425-445, 1995.

BIANCHI, E.; MARTINS, M.; WWEIBLEN, R.; FLORES, E.F. Perfil genotípico e antigênico de amostras do vírus da diarreia viral bovina isoladas no Rio Grande do Sul (2000-2010). Pesqui. Vet. Bras., v.31, p.649-655, 2011.

BOTTON, S.A.; SILVA, A.M.; BRUM, M.C. et al. Antigenic characterization of Brazilian isolates of bovine viral diarrhea virus (BVDV) with monoclonal antibodies and by crossneutralizations. Braz. J. Med. Biol. Res., v.31, p.1429-1438, 1998.

CANAL, C.W.; STRASSER, M.; HERTIG, C. et al. Detection of antibodies to bovine viral diarrhea virus (BVDV) and characterization of genomes of BVDV from Brazil. Vet. Microbiol., v.63, p.85-97, 1998.

DEZEN, S. OTONEL, R.A.A.; ALFIERI, A.F. et al. Perfil da infecção pelo vírus da diarreia viral bovina (BVDV) em um rebanho bovino leiteiro de alta produção e com programa de vacinação contra o BVDV. Pesqui. Vet. Bras., v.33, p.141147, 2013.

FLORES, E.F. WEIBLEN, R.; VOGEL, F.S.F. et al. A infecção pelo vírus da Diarreia Viral Bovina (BVDV) no Brasil - histórico, situação, atual e perspectivas. Pesqui. Vet. Bras.,v.25, p.125-134, 2005.

GIVENS, M.D.; HEATH, A.M.; CARSON, R.L. et al. Analytical sensitivity of assays used for detection of bovine viral diarrhea virus in semen samples from the Southeastern United States. Vet. Microbiol., v.96, p.145-155, 2003.

GIVENS, M.D.; RIDDELL, K.P.; EDMONDSON, M.A. et al. Epidemiology of prolonged testicular infections with bovine viral diarrhea virus. Vet. Microbiol., v.139, p.42-51, 2009. 


\section{Mascitti et al.}

OLIVEIRA, L.G.; ROEHE, P.M.; OLIVEIRA, E.A. et al. Presença de Pestivírus e anticorpos contra Pestivírus em soros e cultivos celulares. Arq. Bras. Med. Vet. Zootec., v.48, p.513-523, 1996.

OTONEL, R.A.; ALFIERI, A.F.; DEZEN, S. et al. The diversity of BVDV subgenotypes in a vaccinated dairy cattle herd in Brazil. Trop. Anim. Health Prod., v.46, p.87-92, 2014.
VILCEK, S.; HERRING, A.J.; HERRING, J.A. et al. Pestiviruses isolated from pigs, cattle and sheep can be allocated into at least three genogroups using polymerase chain reaction and restriction endonuclease analysis. Arch. Virol., v.136, p.309-323, 1994.

WALZ, P.H.; GROOMS, D.L.; PASSLER, T. et al. Control of bovine viral diarrhea virus in ruminants. J. Vet. Intern. Med., v.24, p.476-486, 2010. 